\title{
Religión «oficial» y religiosidad popular en el marco del Real Convento de San Pablo de Sevilla durante el siglo XVIII
}

\author{
Carlos josé Romero mensaque *
}

\section{RESUMEN}

El Real Convento de San Pablo de Sevilla, de la Orden de Predicadores, ha sido desde su fundación en el siglo xill, un centro de capital importancia en la conformación de la religiosidad de la ciudad, tanto en su vertiente ortodoxa u oficial orientada hacia una élite socio-económica, como en la más popular e integradora de las grandes

masas. Durante el siglo XVIII, época de máxima efervescencia de la religiosidad barroca, conviven en este cenobio y bajo la tutela dominica dos significadas corporaciones, que son paradigmas de ambas tendencias.

\begin{abstract}
The «San Pablo» Royal Convent of Seville, of Preachers' Order, has been from its foundation in the century x'II one center of cardinal importance in the conformation of the religiousness of the city, so much in its orihodox or official slope orientated towards a socio-economic elite, since (as, like) in the most popular and of integration of the big masses. During thie century XVIII, epoch of maximum effervescence of the baroque religiousness, they coexist in this monastery and under the guardianship Dominican two important corporations, which are paradigms of both trends.
\end{abstract}

A Fray Fernando Aporta, O.P., historiador de la Orden, in memoriam

En Sevilla, la religiosidad popular adquiere una verdadera carta de naturaleza durante la época del Barroco y la llustración, tras una prolongada

* UNED. Centro Asociado de Seviila. 
y compleja gestación formal tutelada, en primer lugar, por las órdenes mendicantes. El pueblo va adaptando progresivamente las devotas prácticas de piedad popular, llenas de sencillez, claridad e imbuidas de sentimiento sensible, a su propia idiosincrasia cultural, adquiriendo así una identidad propia que, sin dejar de reflejar sus orígenes, supone una real asunción e identificación por parte del pueblo que la vive, sintiéndola realmente como suya. Este proceso se configura en Sevilla, en la segunda mitad del siglo $\mathrm{XV}$, en un ambiente del más aparente que real régimen de cristiandad que se respira.

En el caso de la devoción rosariana, la tutela de la Orden de Predicadores es casi absoluta hasta esta fecha, a través de las Cofradías del Rosario instituidas en varios conventos de la ciudad. Estas corporaciones, prácticamente inéditas hasta el presente para la historiografía sevillana, constituían como una élite bien delimitada socialmente y que practicaban el rezo y devoción avemariana, según los cánones oficiales y ortodoxos emanados de la comunidad dominica y avalados por los muy numerosos documentos pontificios. El Rosario era por entonces un rezo poco divulgado entre el pueblo, circunscrito a la esfera privada o personal, y que sólo en contadas ocasiones se hacía público por los cofrades de estas instituciones.

Conforme la devoción se fue universalizando, al fomentarse desde el siglo XVI su rezo en las numerosas Misiones populares por parte de religiosos de diversas órdenes, el Rosario perdió su exclusivismo y extendió su campo de acción más allá del reducido campo de las cofradías. Surgen paulatinamente hermandades diocesanas, aprobadas por el Ordinario, sin ningún tipo de vinculación con la Orden de Predicadores, lo que era jurídicamente ilegal, pero las trabas formales hubieron de ceder $y$, cuando surge la explosión de los Rosarios públicos, la devoción se hace carismática del pueblo llano y las congregaciones espontáneas surgen por todas partes, muchas de ellas sin más autorización que la de los propios vecinos y otras con la sola del párroco o rector de la iglesia de donde partía el Rosario, incluso de conventos dominicos como el propio San Pablo, casa Grande de la Orden y cuna de la devoción en Sevilla.

Según Ortiz de Zúñiga, ya en 3 de mayo de 1255 hay constancia de una carta plomada, en la que el rey Alfonso $X$ confirma la donación realizada por su padre de urios terrenos a la Orden de Predicadores para labrar el cenobio de San Pablo, siendo su primer prior fray Pedro González Telmo ${ }^{1}$. Su

Ortiz de ZúNiga, Diego, Anales eclesiásticos y seculares. de la ciudad de Sevilla. Sevilla, 1893, año 1255 (4). 
comunidad fue activa y numerosa, formándose en sus aulas los frailes que se embarcaban a los países de misión, primordialmente América. Personajes carismáticos fueron Fray Pablo de Santa Maria en el siglo $\mathrm{XVI}^{2}$ y Fray Pedro de Santa María y Ulloa, el celebérrimo apóstol del Rosario, que entre 1687 y 1690 creó en toda la ciudad un inusitado clima de fervor hacia el rezo y la devoción, que hizo de San Pablo lugar de encuentro de auténticas multitudes que a diario acudian a escuchar sus pláticas ${ }^{3}$.

Las cofradias dominicas, en especial la primitiva Cofradia de este convento, constituyeron un modelo formal para estas congregaciones y posteriores hermandades, muchas de las cuales agregaban sus integrantes a la Cofradía para lucrarse de las gracias e indulgencias concedidas al Rosario por la Santa Sede, pero sin vinculación formal alguna. Se registraron incluso pleitos sobre el título rosariano por parte de esta Cofradia, aunque a la postre hubo de admitirse que el Rosario en Sevilla había dejado de tener una única tutela y ortodoxia ${ }^{4}$.

En este artículo quiero presentar a estudio un ejemplo de convivencia de ambas religiosidades: popular y uoficial» en torno a la devoción del Rosario y en el marco más significativo: el ya citado Real Convento de San Pablo. Por un lado me referiré a la Primitiva Cofradía del Rosario, institución elitista, netamente dominica, dedicada al culto interno y cuyos orígenes se remontan al siglo $\mathrm{xV}, \mathrm{y}$ por otro a una congregación modesta, la de Nuestra Señora del Consuelo, iniegrada por vecinos de la collación, dedicada al ejercicio del Rosario público, que tuvo una existencia efímera $e$ inestable en esta centuria... pero que, igualmente, estaba tutelada por los frailes dominicos del cenobio.

Formalmente la Cofradía era el medio privilegiado a través del cual la Orden marcaba las pautas de la devoción rosariana, pero, como ya se ha indicado, una vez desaparecido no sólo el monopolio del rezo, sino la propia iniciativa del mismo respecto a las masas populares, se observa un

\footnotetext{
2 Moreno, J., La vida y muerte y grandes milagros que el Señor ha hecho por el V. Fray Pablo de Santa María. Sevilla 1606.

3 Sobre su figura, aún por estudiar, es útil la reseña de ARANDA, Gabriel de, Vida del siervo de Dios... el venerable Fernando de Contreras. Sevilla, 1692, págs 891 y ss.

4 Se trata de un sonoro pleito sostenido en el siglo XVI con las hermandades penitenciales de la Oración del Huerto y Nuestra Señora del Rosario, del cenobio dominico de Monte Sión y otra denominada de la Virgen del Rosario, formada por negros en el barrio de Triana. Cfr. Expediente de 1585 que se conserva en el Archivo Sacramental de la Magdalena. Vid. también RoMERO MENSAQUE, CarloS J., "Cotidianidad, dinamismo y espontaneidad en la religiosidad popular: el fenómeno de los Rosarios públicos en la Sevilla del Barroco", en Espacio, tiempo y forma, serie $I V, H^{a}$ Moderna, t. 11, 1998, págs 215-238.
} 
planteamiento pastoral de acercamiento a las nuevas sensibilidades rosarianas, tanto en lo material o estético como a la nueva religiosidad que subyace. Se constatan iniciativas en el ámbito de las cofradías, pero pronto se advierte que es necesario integrar en la tutela pastoral de la Orden, las nuevas congregaciones o hermandades dedicadas al ejercicio del Rosario público. De esta manera, la Orden recupera en parte su capacidad de liderazgo en el fenómeno popular del Rosario, en reñida competencia con los capuchinos, sobresaliendo la figura carismática de fray Pedro Vázquez Tinoco, que protagonizó en la década de los 30 una reactivación de los cortejos con la instauración de su modalidad femenina e infantil ${ }^{5}$.

Paulatinamente el real convento de San Pablo, casa principal de la Orden en Sevilla, se va constituyendo de nuevo en este siglo XVIII en el centro fundamental de referencia para la devoción del Rosario en Sevilla. Cada noche y madrugada son varios los Rosarios públicos que hacen estación al cenobio, y asisten a ejercicios y pláticas que se celebran "ad hoc". Pero sin duda supuso un jalón indiscutible en esta trayectoria la erección en el propio cenobio de una congregación del Santo Rosario, que se constituyó en una instancia de raigambre popular, pero que a la vez servía de cauce de comunicación directa con los Rosarios públicos y sus cientos de congregaciones o hermandades. Esto ciertamente supuso un elemento integrador de la religiosidad popular en el cenobio dominico, aunque no van a faltar momentos y circunstancias que evidencian que los cofrades se sentian un tanto coartados en sus actividades por la tutela del padre capellán, y aun a veces de forma inconsciente, la corporación carecía de la espontaneidad y autonomía de que gozaban otras congregaciones del mismo instituto.

Durante esta centuria, mientras la Cofradía del Rosario consolida sus estructuras institucionales en una actividad regular de gobierno y administración de patronatos, la Congregación de la Virgen del Consuelo vive siempre en una situación de constante precariedad dependiendo para su sostén de las limosnas y donativos de vecinos y devotos. De hecho, esta Congregación es fruto efímero del fenómeno de los Rosarios públicos $y$, con la crisis de fines del siglo XvIII y la progresiva desaparición del "régimen de cristiandad barroca" se extinguió rápidamente. Por el contrario, la Cofradía, tras superar la Real Orden de Carlos III sobre supresión de hermandades, continuó con su instituto hasta la Exclaustración de San Pablo, atravesando posteriormente una grave crisis que le condujo a fu-

Cir. Romero Mensaque, Carlos j., op. cit. 
sionarse temporalmente con una hermandad penitencial, la de Montserrat (1867-1948), perdiendo gradualmente su condición jurídica de Cofradía y convirtiéndose ya de derecho en una hermandad de Gloria diocesana.

\section{LA PRIMITIVA COFRADIÁ DEL ROSARIO}

No se puede entender el fenómeno rosariano en Sevilla en la época del Barroco si no se complementa el estudio de las hermandades diocesanas, indudablemente más populares y arraigadas entre los sevillanos, con el de las cofradías dominicas como la que nos ocupa. La Cofradía de San Pablo representa la ortodoxia formal de la devoción rosariana, en tanto corporación dependiente y tutelada por la Orden de Predicadores y detentadora de bulas y privilegios pontificios, que concedian gran cantidad de gracias e indulgencias para todos los cofrades propios y agregados. Según la legislación canónica entonces vigente, no se podía erigir en una ciudad una corporación rosariana si no era con expresa licencia de la Orden de Predicadores $y$, por tanto, toda persona que quisiera lucrarse con las gracias e indulgencias del Rosario debía agregarse a la Cofradía instituida en cada localidad, pues sólo se podía autorizar una. En el caso de Sevilla era la Cofradía de San Pablo, aunque posteriormente se autorizasen otras cofradias en cenobios dominicos.

El P. Sagredo, en sus notas históricas sobre el convento de Regina Angelorum, afirma, citando un libro antiguo de la Cofradía del Rosario de dicho cenobio, que en 1481 se fundó la Primitiva Cofradía de Sevilla en el real convento de San Pablo ${ }^{6}$.

Este dato viene confirmado por otras dos fuentes, una de ellas proveniente de la propia Cofradía. La primera es el expediente acerca del pleito que sostiene esta Cofradía de San Pablo con la Hermandad de la Oración en el Huerto de Monte Sion sobre e! uso del título rosariano, en el que se da por probada una antigüedad de más de cien años respecto a la fecha del expediente, $1585^{7}$. La segunda es una obra manuscrita sobre la historia del convento de San Pablo, de la que es autor fray Francisco Ra-

- Sagredo, J., La Hermandad del Rosario del convento de Regina Angelorum de la Orden de Predicadores y la Real Maestranza de Caballeria. Sevilla, 1923, pág. 13.

Archivo Sacramental de la Farroduia de la Magdalena, Expediente del plejto por el título rosariano. En los últimos folios se anota: «[...] con lo que mi parte (Rosaric de San Pablo) ha más de cien años que está fundada y erigida en esta ciudad con autoridad y aprobación de la Santa Sede Apostólica y del Rvdmo. General de la Orden de Santo Domingo [...]" 
mírez de Solórzano, y que textualmente dice: "Comenzó a volar por Europa la fama milagrosa del Rosario y llegó al convento de San Pablo de Sevilla la noticia de la institución de la Cofradía de Alemania y el año de 1480, poco más o menos, la instituyó en él fray Alonso de Ojeda, que era prior y florecía en aquel tiempo" ${ }^{8}$.

Todo ello nos confirma la existencia de la Primitiva Cofradia del Rosario de Sevilla en los años finales del siglo XV, siendo muy probable la verosimilitud exacta del año que cita Sagredo, que, sin duda, podrá corroborarse con nuevos aportes documentales.

Según refiere Solórzono, la comunidad dominica cedió a la Cofradía una de las capillas de su iglesia, pero pronto los cofrades obtuvieron licencia de la Mitra hispalense, que ocupaba el dominico fray Diego de Deza (1505-1523), para labrar rica y amplia capilla tras la compra de dos casas cercanas al convento. Esto indica los importantes recursos económicos con que contaba la corporación, más si tenemos en cuenta que sus cofrades pertenecian a la nobleza de la ciudad. Esta característica social de sus cofrades va a ser predominante en los siglos siguientes, aunque en la segunda mitad del siglo XVII parece detectarse un importante alza del número de cofrades y una mayor diversificación social, con predominio de elementos de la alta burguesía de la ciudad, escribanos públicos y funcionarios judiciales, capitanes y profesiones liberales. Esta apertura se debió, sin duda, a la importancia del Rosario tras la coyuntura de la pestilencia de 1649, y al auge que desde entonces tomó como devoción central de todas las Misiones populares, en las que el convento de San Pablo era uno de los focos más importantes ${ }^{9}$.

En estas circunstancias, la Cofradía se nos presenta en el siglo XVII como una corporación ciertamente elitista, un tanto alejada del movimiento popular rosariano y las hermandades diocesanas, aunque tenía relaciones con algunas de ellas, y conservando, como queda dicho, cierta preeminencia espiritual. Sus actividades son, en general, de carácter interno, salvo

- Pamialez de Solorzano, F., Historia del Santo y Real Convento de San Pablo de Sevilla, de la Orden del Glorioso Patriarca Santo Domingo de la Provincia de Andalucia... Debo la referencia al que fue gran historiador de la Orden fray Fernando Aporta (q.s.g.h.).

9 Archivo Sacramental de la Parroquia de la Magdalena, Libro de cofrades del siglo xVH. No es posible trazar un perfil concreto de los cofrades respecto a su extracción social, ya que no se conservan libros de ingreso. No obstante, en las entradas correspondientes a la segunda mitad del XVil se observan las características indicadas. Incluso se atisba una mayor apertura por cuanto existen patronatos destinados a dotar doncellas pobres, en los que tienen preeminencia las hijas de cofrades, pero el estudio de actas y cuentas parece deducir que se trataria de excepciones. 
la procesión en el mes de octubre prácticamente. En ello influyó notablemente la tutela dominica, que imponía una ortodoxia rosariana que marcaba sus cultos y ejercicios, restándoles la espontaneidad y arraigo de las prácticas callejeras. En el aspecto económico contaba con importantes propiedades y administraba diversas fundaciones testamentarias. Esto le hacia contrastar todavía más con el resto de las hermandades rosarianas, que, en general, dependian del pueblo y sus limosnas para la subsistencia. En el caso que nos ocupa, su potencial económico le hizo posible una autonomía importante ante la comunidad de San Pablo.

Del siglo XvII existe un libro de hermanos cuyas partidas abarcan desde 1613 a 1695, es decir, casi la totalidad de la centuria, siendo en su segunda mitad cuando se experimenta el mayor número de entradas, coincidiendo con la época en que la devoción del Santo Rosario comenzaba a adquirir en la ciudad una mayor incidencia.

Destaca el hecho de que estas partidas o bien son individuales, de varones únicamente (salvo las viudas de cofrades) o bien de estos con su mujer o su madre, resultando este el único modo al parecer de acceso de las mujeres a la Cofradía. Entre los 582 cofrades inscritos en el libro, hay que decir que abundan los apellidos ilustres, caballeros de la Orden de Santiago, abogados y procuradores de la Audiencia, capitanes, etc. Cabe destacar al capitán Miguel de Benavides, recibido en 1648 y que donó un retablo de la Virgen y, sobre todo, el gran pintor universal Bartolomé Es. teban Murillo, recibido en 1644 y que fue cofrade hasta su muerte ${ }^{10}$.

Gran actividad desarrolla la Cofradía durante el siglo xvIII. De esta época se conservan dos libros de cabildos y uno de cuentas que nos indican que la corporación gozaba de un patrimonio importante y administraba varias rentas, memorias y patronatos.

Quiero centrar el estudio de la Cofradía de San Pablo, en tres aspectos claves para analizar su trayectoria histórica: Régimen de gobierno, Actividades Culturales y Religiosidad, y Patrimonio y Economía.

Y para analizar estos apartados, voy a tomar como base documental los libros de actas y acuerdos y el libro de cuentas de la Cofradía, que se conservan en el Archivo Sacramental de la parroquia de Santa María Magdalena y que abarcan más de la mitad del siglo XVIII. En su mayor parte,

10 idem, libro de hermanos, sin techa, del siglo xvII. El capitán Benavides fue un gran favorecedor de la Hermandad. Su cédula se encuentra erı el folio 118. I.a del célebre pintor figura en el 108 , siendo su admisión en 7 de tebrero. 
estos libros presentan un grave deterioro físico. De hecho, algunos datos, sobre todo respecto a las actas capitulares, resultan ilegibles debido al pésimo estado de conservación en que se encuentran, fruto de la humedad y la polilla, y otros han podido ser rescatados más por intuición que por lectura directa.

Esta documentación nos permitirá conocer detalles inéditos y harto significativos, del acontecer de esta corporación, sobre todo en los aspectos culturales y administrativos, y servir asi un avance de un estudio más sistemático de las cofradías dominicas de Sevilla, de las que, la que nos ocupa, era su prototipo. Una carencia sin duda significativa, son las Reglas que regían su vida y que no se han conservado en el archivo, aunque la propia información de actas y cuentas remedian en parte esta laguna. Existen las ordenanzas generales de la Cofradía del Rosario aprobadas por el Papa, pero éstas se adaptan a las circunstancias concretas de la localidad donde se erige ${ }^{11}$.

\section{El régimen de gobierno}

El gobierno de la Cofradía se basaba en la Junta de Oficiales, que constaba de los siguientes cargos: alcalde antiguo, alcalde moderno, mayordomo de hacienda, mayordomo de bienes, fiscal, dos secretarios, diputados y un contador, cargo que en principio no fue incluido entre los oficiales, sino que tenía carácter de empleo remunerado. Además de estos cargos gubernativos había otros como el muñidor o criado de la Hermandad y el portero, posteriormente denominado capiller, que, como su propio nombre indica, cuidaba de la capilla y enseres de la Cofradía. En un cabildo de enero de 1763 aparece también la figura del prioste dentro de la estructura de la junta de gobierno - lo que era común en las cofradías dominicanas de la provincia-, pero se trata de un caso aislado, que no se explica fácilmente, pues no vuelve a aparecer en ocasiones posteriores. El prioste, en las constituciones generales del Rosario, era el principal cargo de gobierno de una Cofradía. No obstante, en

11 La documentación sobre las cofradías dominicas no es siempre fácil de localizar e investigar, debido a las múltiples incidencias ocurridas en el siglo XIX con las exclaustraciones de sus conventos. Sobre éstas trazo una breve reseña en "El Rosario público en la Sevilla del siglo XVIII. Datos para un repertorio de Cofradias, Hermandades y Congregaciones del Santo Rosario" en Actas del l Congreso sobre Advocaciones Marianas de Gloria, Córdoba, Cajasur, 2003. En prensa. 
las Reglas de la de Carmona (1522), aparece este cargo como el encargado de cuidar los enseres de la Cofradía, mientras que la presidencia de la junta la ostentan los alcaldes, como en la generalidad de las hermandades diocesanas ${ }^{12}$. El no contar con las Reglas vigentes impide mayor clarificación.

Las elecciones a la junta de gobierno tenían carácter anual, celebrándose ordinariamente a finales de diciembre o primeros de enero. En la época a estudio, cabe decir como características del sistema electoral, que en toda elección había una propuesta de candidatura de la junta de gobierno saliente, reunida previamente en Cabildo de Escrutinio y otra de diputados electos por los hermanos asistentes al Cabildo de Elecciones. Al final se elegía, por mayoría de votos, en los cargos en que no hubiese coincidencia.

Los cofrades elegían siempre no a los dos alcaldes, sino sólo al segundo o moderno, ya que éste, por Regla, debía ocupar el puesto de antiguo al año siguiente, en que sería elegido su sucesor. El cargo de secretario tenía el mismo procedimiento. Estas disposiciones para el principal oficio de la Hermandad, hacían que éste fuese limitado en sus poderes y muy controlado por los cofrades. Mayor independencia y responsabilidad recaía en los mayordomos, sobre todo el de Hacienda, responsable directo del patrimonio de la Cofradía y que, junto al de Bienes, administraban su economía.

En realidad, no nos es conocida de forma exacta la diferenciación de competencias de ambos mayordomos, pero el desarrollo de algunos cabildos, donde el mayordomo de Hacienda se presenta como el gran responsable del ámbito económico, nos hace pensar en su mayor importancia. En este cargo destaca en esta etapa Bartolomé Herrero de Vega, que durante treinta años vino ejerciendo sus funciones, siendo reelegido sis-

12 Concretamente aparece como prioste, de manera aislada, el cofrade Manuel Angulo en acta de 2 de enero de 1763 y anteriornente Cristóbal de Saavedra. En las constituciones generales de las cofradías, tal y como se recoge en el Expediente citado, se dice que "[...] de aquellos que quisieren ser cotrades escoja (el prior) algunas personas principales y devotas y los ponga por oficiales de esta Cofradía poniendo en cada pueblo un Prioste y dos alcaldes mayordomos [...]» Sin embargo, en las Reglas de Carmona (cfr Sanchez Herrero, José (ed) CXIX Reglas de Hermandades y Cofradias andaluzas. Siglos XIV, XV y XVI. Huelva, Universidad, 2002, págs. 161-162. La tráscripción y estudio ha sido realizado por el autor de este artículo) el prioste es el que "[...] dará buena cuenta de la cera y los bienes que se le entregaren y así plata, tributos, ropa, vestidos y dineros y todos los demás bienes y prendas de la Cofradia han de estar a su cargo [...]" Es posible que el prioste sea un delegado del prior designado de entre los coirades. 
temáticamente hasta su fallecimiento y que fue caso único de permanencia tan prolongada ${ }^{13}$, aunque se constata cierta estabilidad en el cargo.

Los diputados se denominaban de Hacienda y eran doce, con una responsabilidad parece que rotativa mensualmente, en la que eran los encargados de la administración, probablemente de las cuotas, y demandas bajo la supervisión del mayordomo.

Índice de la actividad gubernativa de la Cofradía, son los cabildos. En esta cuestión es preciso hacer una división previa. Efectivamente, existen tres grandes tipos de cabildos: Cabildo General de Elecciones, Cabildo General de Hacienda y Junta de Hacienda.

Los más comunes eran los generales, en los que participaban todos los cofrades y de entre los cuales, el ordinario, es decir, el que anualmente siempre tenía lugar, era el de Elecciones. Los cabildos de Hacienda eran también generales, primordialmente para discutir cuestiones de legados o memorias al igual que las Juntas, aunque éstas restringidas sólo a los principales cargos de la Mesa de gobierno.

Salvo en el caso en que aconteciera algún suceso notable que hiciese conveniente la convocatoria de un Cabildo general extraordinario, el más importante a lo largo del año era el de Elecciones, presidido por el prior del convento de San Pablo como presidente nato de la Cofradía, el cual, mediante una fórmula ya tradicional, recibía solemnemente como nuevos cofrades a todos los que se hubieran inscrito durante ese año. Además de los cargos directivos, en este cabildo se elegían a los braceros, es decir, a los quince hermanos que en la Procesión Anual conmemorativa de la Batalla de Lepanto, portarían al Paso o parihuela de la imagen de Nuestra Señora del Rosario por las calles de la feligresía.

Pasando a las estadísticas, cabe decir que, por quinquenios, se destaca una gran frecuencia en las convocatorias de cabildos generales: 1731-1735: $14 ; 1736-40: 24$, con un total de nueve solamente en 1739. Igualmente se dan períodos de cierta languidez, 1741-1745 y 1746-1750, recuperándose en parte en la década de los cincuenta, y volviendo a decrecer aproximadamente a una media de uno o dos anuales hasta finales de siglo.

Respecto a las Juntas de Hacienda, no se celebran de manera regular, sino esporádica, hasta los años cincuenta, siendo a partir de 1770 ordinarias a lo largo del año en mayor número que los cabildos generales.

13 Archivo Sacramental de la Magdalena, libro $1 .^{\circ}$ de cabildos de la Cofradia, acta capitular de 29-6-1751. El Mayordomo citado presenta la dimísión por enfermedad. 
Estas cifras son sintomáticas del mayor o menor grado de actividad en la Hermandad, así como de la participación efectiva de los cofrades en el gobierno de la corporación (Cabildos Generales) o el carácter de cierta pasividad que circunscribe la actividad y el gobierno a los oficiales (predominio de las Juntas de Hacienda).

\section{La actividad cultual y la religiosidad}

Las celebraciones cultuales de la corporación pueden ser divididas y concretadas en tres grandes esferas: Culto Ordinario o Ejercicios - Funciones y Procesión- Sufragios. Otro aspecto serán los referidos a la religiosidad.

\section{a) Cultos ordinarios-Ejercicios}

- Rezo semanal de los quince Misterios del Rosario.

- Procesiones mensuales «mensales» de la imagen de Nuestra Señora del Rosario los primeros domingos de mes y, sobre todo, en las fiestas de la Purificación, Asunción y Natividad de la Virgen. Se celebraban alrededor de las naves de la iglesia.

- Función Principal del primer domingo de octubre, instituida en conmemoración de la victoria de Lepanto ${ }^{14}$.

Además de estas actividades obligatorias, propiamente de instituto, la Cofradía celebraba una serie de misas en cumplimiento de diversas memorias que administraba y que, en su momento, se conocerán.

Igualmente se celebra una Fiesta de Rosas el primer domingo de mayo, tradición de mucho sabor y liturgia muy rica en matices, con la bendición solemne de las rosas, símbolo de la advocación ${ }^{\text {i5 }}$.

14 Archivo Sacramental de la Parroquia de la Magdalena, Libro de Cuentas. Data de 174749. A modo de ejempio, los gastos de la Fiesta Naval de octubre: organista, clarín que asistió toda la noche y todo el dia de fiesta, Sacristanes por los repiques y luminarias, fuegos que se queman las visperas y dia de fiesta, Asistencia de la Música de la Colegial del Salvador a la procesión por las calles, Danza que ha asistido cada año a la procesión (danzá de espadas), Madres beatas (las vestidoras de la Virgen). Muñidor de la Hermandad y Mozos que llevan las andas en la procesión.

15 ídem. Se hace referencia a esta Fiesta de la Rosas que dotó Ángela Ortiz de Briones, viuda de José de Olaizola, Caballero de la Orden de Santiago, en torno a 1743. Se establecen varios gastos por predicadores, mozos para llevar las andas en la procesión y por las rosas de la Hermandad. Vid. data de 1747-49 
El rezo semanal del Santo Rosario, considerando los quince Misterios, era la primera obligación de los cofrades del Rosario, la primera que aparecia en las bulas pontificias, pues constituía uno de los pilares fundamentales de la fundación.

\section{b) La Procesión anual}

La Procesión mensual o mensal se llevaba a efecto de manera ordinaria los primeros domingos de mes y con mayor pompa en las festividades reseñadas ya. La principal de todas ellas era sin duda la del primer domingo de octubre, coincidente con la Función Principal a Nuestra Señora del Rosario.

La particularidad primordial que esta Procesión tenía respecto a las otras es que era pública, es decir, salía extramuros del convento a fin de recorrer las principales calles de la feligresía. En las actas se recogen varias circunstancias de la misma que, a continuación, voy a referir.

Así, en 1732 se conserva el orden del cortejo y parte del itinerario. La Procesión salió por la puerta de la calle Real del convento y se dirigió por la calle del Ángel, donde fue recibida por la comunidad de los Carmelitas Descalzos con las puertas abiertas, y todo el templo iluminado. Posteriormente fue por Cerrajería, Colegio de San Acacio, donde fue recibida de manera parecida. Luego discurrió por la calle de la Muela... El resto de la relación no se conserva, por humedades del manuscrito ${ }^{16}$.

El cortejo formó así:

- Cruz del convento.

- Cofrades entremezclados con religiosos.

- "Cuerpo de procesión con las danzas y músicas que se acostumbra».

- Estandarte de la Cofradía en medio del cuerpo y en él, dos parihuelas con el Patriarca Santo Domingo y San Pío V.

- Imagen de Nuestra Señora en sus parihuelas.

- Preste y diáconos del convento.

Se hace constar de forma destacada que la parroquia de Santa María Magdalena no asistió. En ello quizá influyese la Bula papal de 1724, por

16 idem, libro 1. ${ }^{\circ}$ de actas, fol. 1 , nota de 1732. 
la que se autorizaba a la Orden de Predicadores a llevar a efecto Solemne Procesión por las calles de la feligresía de su convento, sin previa autorización del Ordinario Diocesano. Se sabe que cuando esta nueva se conoció en Sevilla, se registraron diversos altercados entre la comunidad de San Pablo y el prelado y clero parroquial, actitud que se mantenía.

Parecida circunstancia aconteció en 1742, en que la Procesión llegó hasta Triana, haciendo estación en el convento de las Mínimas, donde fue recibida de forma solemne en el compás, en cuyo interior se había colocado un altar "ad hoc". Se describe en el acta capitular todo el ceremonial pomposo, contrastándolo con la fría recepción de la parroquia de la Magdalena, que, aunque permaneció abierta al paso de la Procesión, se abstuvo de hacer repicar las campanas, no demostrando intención alguna de especial deferencia dada la vecindad. Se añade que esta actitud de cierta enemistad entre clero regular y secular se había ya obviado en Triana, donde la parroquia recibió solemnemente a la procesión del convento de San Jacinto ${ }^{17}$.

Durante la segunda mitad de siglo se conserva en acta también, concretamente en 1778, el itinerario que llevó a efecto la Procesión y que por vez primera aparece completo y nos permite hacernos una idea más documentada de este culto anual, aunque es posible que sufriese variaciones en los diversos años. El texto dice que... "se acordó que saliere por la puerta de San Femando, que está frente a la portería, tomase la puerta de Triana, siguiese a la Pajería, torciendo a calle Catalanes hasta llegar a la Cárcel real y desde allí a la calle de la Sierpe hasta la cruz de la Cerrajería, tomar calle del Ángel, derecho al convento de San Pablo, entrando por la puerta que se avista a la calle de las Tiendas. En el transcurso de esta procesión fue recibida por los padres franciscanos en su Casa Grande y los Carmelitas del Santo Ángel y San Buenaventura» ${ }^{18}$.

En lo referente al aspecto material de estas procesiones hay que decir que la imagen de la Virgen era vestida como dama y contaba con un rostrillo de diamantes. Realizaba la salida procesional en un Paso con tumbilla sostenida por varales de plata. Sin embargo, en 1786, a propuesta del

17 Ibidem, libro $2{ }^{\circ}$ de actas, nota de 174\%. [...] "y aunque la puerta de Santa Maria Magdalena estuvo abierta, no repicaron las campanas ni colgaron las paredes ni hicieron demostración alguna les beneficiados y clero de ella, aunque habían asegurado que repicarían como lo habían hecho el año antecedente, y se ejecutó en Señora Santa Ana con la procesión que sale de San Jacinto".

18 Ibidem, libro $2 .^{\circ}$ de actas, nota 1778. 
prior del convento, se acordó una remodelación en la forma de vestir la imagen y, así mismo, del Paso procesional ${ }^{19}$.

Respecto a lo primero, se quería que la imagen fuese vestida como la generalidad de las Vírgenes de Gloria de la ciudad, suprimiéndose las prendas antiguas y el rostrillo. Esta remodelación de la vestimenta tenía aplicación no sólo procesional, sino también para el culto ordinario de altar.

El Paso también sufrió modificaciones al desaparecer la tumbilla y adquirirse una nueva peana y sobre todo unas ráfagas, que fueron elaboradas en parte con la plata de los varales. De esta manera, la estética procesional de la Cofradía se adaptaba a la época, perdiendo su peculiar estilo en aras de los usos convencionales de las demás imágenes marianas y de la mejor captación de la devoción popular.

\section{c) La religiosidad}

Las cuestiones relativas a la Procesión denotan claramente un clima grave de tensión en la Iglesia sevillana entre seculares y regulares, en estos temas de religiosidad popular en donde tantos intereses están en juego: la atracción de la feligresia, el predominio en las iniciativas pastorales y las correspondientes repercusiones económicas en forma de limosnas, donativos o memorias testamentarias. Las prerrogativas concedidas a las órdenes, que le concedían amplia autonomía frente a la jurisdicción ordinaria, se manifestaba de forma considerable en cuestiones como la que nos ocupa, pues el Rosario y su devoción constituían la mayor manifestación de piedad popular en la Sevilla de entonces.

19 Ibidem, actas capitulares de 31-12-1734 y 5-8-1736. En el primer cabildo se abordó el tema de la hechura de un nuevo rostrillo realizado en oro y diamantes, a fin de sustituir al que entonces tenía, que era de poca calidad. Para ello se contaba con las piedras y el metal precioso donados por un cofrade. Para la hechura se acuerda estudiar la enajenación de alhajas menores. En el cabildo de 1736 se muestra a los oficiales este rostrilo ya confeccionado, del que todos los presentes se muestran muy satisfechos. Sin embargo, la junta de Hacienda de 10-9-1786, a la que asiste el Prior del convento, el cual habia tenido en fechas anteriores algunas diferencias con la Cofradia, no teniendo voluntad de asistir el año anterior con la comunidad a la Procesión de la batalla Naval (acta capitular de 2-10-1785), quien propone las medidas comentadas, haciendo hincapié en la necesaria adaptación a las costumbres del resto de las hermandades. En junta de Hacienda de 28-10-1786 se ratifica el acuerdo de que se vista la Virgen "al uso del dia".

Se produce una auténtica conmoción en la diriámica de la Cofradía, que con suma celeridad enajena el rostrillo y la vestimenta antigua, e inclusc se hacen reformas en la imagen de la Virgen para adaptarle los nuevos vestidos. 
Pudiera incluso plantearse, como hipótesis de trabajo, si la rápida difusión del Rosario en Sevilla y la creación de tantas hermandades y congregaciones rosarianas de carácter diocesano independientes de la Orden de Predicadores, no fue en parte también consecuencia de este clima de rivalidad en la pastoral popular, pues lo cierto fue que muy pronto vino a desaparecer el exclusivismo dominico sobre el Rosario, de lo que la propia Cofradía que nos ocupa se queja amargamente, como ya se comentó.

Es incontestable esta preocupación de estos dos elementos clericales respecto a la religiosidad popular, en este caso rosariana, pues su pastoral se presenta problemática. Tras la desaparición fáctica del monopolio dominico, el pueblo va a tomar como suya la devoción, y las congregaciones y hermandades elaborarán su propia "ortodoxia" y "ortopraxis", centrada en los Rosarios públicos, que escapan en general de cualquier tutela, sea secular o regular.

En este sentido hay que entender el cambio de la estética de la imagen y el Paso procesional, adaptándolo a las costumbres de las hermandades diocesanas del Rosario, que gozaban de gran predicamento popular. Y la iniciativa parte del prior, denotando así la intervención de la Orden de Predicadores en la conformación del aspecto más adecuado de cara a la piedad popular. Hay una preocupación pastoral por adaptar las formas de una Cofradía dominica a una realidad menos estática y uniforme, y más acorde con la religiosidad barroca, plena de sentimiento y emoción.

La Cofradía de San Pablo trata de hacer valer sus prerrogativas y fomenta la adscripción popular en sus libros de cofrades para hacerse acreedor de las gracias e indulgencias pontificias que sólo ella, como entidad oficial rosariana reconocida, podía facilitar a los fieles. El adscribirse de esta forma no significaba la entrada en la Cofradía, sino sólo una especie de agregación secundaria. Ya hemos hablado del carácter elitista de la corporación, pero éste no le impedía un acercamiento a la piedad popular, que repercutía positivamente en sus intereses.

Este medio seguía siendo importante y le hacía conservar a la Cofradía ese predominio antes comentado entre el resto de las corporaciones rosarianas diocesanas, que adscribian en los libros de San Pablo a sus cofrades y entre el pueblo en general con el devoto ejercicio igualmente de los libros de Horas, en los que se anotaban los nombres de los fieles y las horas en que les correspondía el rezo de unos determinados Misterios, a modo de lo que hoy es el Rosario perpetuo. Estas prácticas devotas estaban bastante arraigadas y suponían la dimensión un tanto interna de la devoción rosariana, que completaba en menor escala la dimensión pro- 
cesional de los Rosarios públicos y que constituía como un ámbito privilegiado para la Cofradía de San Pablo.

Por esta razón cuidaba con esmero estas cuestiones. En las actas capitulares se refleja todo esto, y de manera particular, en ocasión a un contencioso con la Orden Tercera radicada en el mismo convento, que intentó beneficiarse también de estas prácticas. En una Junta de Hacienda de enero de $1778^{20}$, el alcalde antiguo hizo presente que «correspondiendo privativamente a esta hermandad el uso de los libros donde el común de los fieles se sientan y suscriben sus nombres para ganar las gracias e indulgencias concedidas.., a los cofrades del Stmo. Rosario, haciendo el asiento en dichos libros el P. Prior o el religioso a quien haga sus veces, sin que pueda haber en la iglesia mesa ni demanda alguna del Rosario más que la que está a la puerta de nuestra capilla y repartirse en ella las horas que llaman del Rosario, sucede que, en contravención de lo dicho, en la mesa y demanda de la Orden Tercera de N. P. Sto. Domingo, hay igual libro y horas del Rosario, vendiéndose éstas a los que las piden y sentando en el libro a los que quieren recibirse por cofrades.., no teniendo facultad dicha Orden Tercera...».

Se añade que no era la primera vez que ocurría esta circunstancia, que ciertamente atentaba con unos derechos reconocidos a toda Cofradía del Rosario.

\section{El patrimonio y la economia}

\section{a) El patrimonio}

El patrimonio de la Cofradía nos es desconocido en gran parte, pues no he podido hallar ningún inventario de bienes de la época.

No obstante sí conocemos que era propietaria de una Capilla, la actual sacramental de la Magdalena, mediante escritura de compra otorgada por la Comunidad de San Pablo en 27 de octubre de 1716 de un solar de cuarenta y siete varas, en que también edificó la denominada "Casa del Rosario» 21 .

20 archivo sacramental de la Parroouia de la Magcalena, libro 2. de actas, acta capitular de 14-3-1778.

21 archivo Hermandad Rosario de la Magdalena, Inventario protocolizado ante el Notario D. Cristóbal Moreno Sánchez, 20 de enero de 1942. 
A través de actas y cuentas pueden rastrearse algunos datos de manera esporádica. Así, por ejemplo, se constata la existencia de dos imágenes de la Virgen del Rosario, además de la titular; una que se encontraba en la sala capitular y tenía la finalidad de ser colocada en el altar cuando la titular era trasladada para las procesiones, y otra que se adquirió de forma exclusiva posteriormente -1786 - para estas procesiones mensales, por lo que la primera dejó de desempeñar su función salvo quizá el domingo de la Fiesta Naval (primer domingo de octubre), en que era la imagen titular la que, sin duda, era procesionada por las calles de la feligresía ${ }^{22}$.

Es interesante también recoger los objetos que en 1756 se hallaban en el arca de la Cofradía cuando tiene lugar una apertura oficial que recoge un acta: Rostrillo de diamantes, gargantilla de lo mismo, rosario engarzado en oro, dos pulseras de perlas finas de doce hilos y un peto de esmeraldas. Junto a ellos, la Cofradía poseía un rosario de oro de cinco dieces con los padrenuestros y otros intermedios de perlas y tres medallas de oro, que custodiaba la comunidad dominica, y también un Sagrario de plata que se adquirió en $1764^{23}$.

Igualmente, poseía una capilla y casa aneja adosada a la iglesia, que subsisten en la actualidad ${ }^{24}$.

\section{b) La economía}

En el capítulo económico no son mejores las perspectivas que nos ofrecen los libros reseñados. Siguiendo el libro de Cuentas, los principales conceptos en ingresos y gastos a lo largo del año eran los siguientes:

- Ingresos:

- Rentas ordinarias

- Entrada de hermanos

- Limosnas y averiguaciones

22 Archivo Sacramental de la Magdalena, libro 1. de actas, acta capitular de 17-6-1753. En esta junta de hacienda se acuerda adecentar y colocar en la sala capitular, una pequeña imagen de la Virgen del Rosario de una vara de alto, y se le haga un rostrillo verdugado y se la deposite en el altar cuando se quite la titular. Respecto a la imagen a utilizar en las fiestas mensales, vid. la juntá de 10-9-1786 siendo iniciativa del prior del convento, la adquisición.

23 ídem, acta capitular de 8-1-1756. El dato del sagrario de plata es del cabildo de 5-8-1764.

24 Archivo Hermandad del Rosario, Papeles diversos del siglo xx, Informe sobre la Casa del Rosario, 1948. 
- Gastos:

- Tributos a abonar

- Memorias de misas

- Reparaciones y varios en las casas que posee

- Cera

- Fiestas anuales y Procesión

- Sufragios por difuntos

No es ocasión de detallar aquí las distintas rentas ordinarias de la Cofradía, ni tampoco los tributos ni Memorias que administraba y que constituian un número importante. Sin duda, su carácter de Cofradía del Rosario, con sus gracias y privilegios, tanto a vivos como a difuntos, hacía que muchas personas le otorgasen legados de muy variado concepto. De ahí que la administración resultase complicada y una gran problemática se planteó con ella a la Cofradía. Su responsable máximo era el mayordomo de Hacienda, quien contaba con auxiliares tales como un cobrador o administrador, con el que hubo diversos conflictos muy desagradables, que culminaron con la supresión o, más bien, unificación de este cargo con el de portero o muñidor de la Cofradia ${ }^{25}$.

Me referiré solamente a dos interesantes patronatos, el de Miguel Jerónimo, que dotaba doncellas que iban a tomar estado, con la condición de ser hijas de cofrades, teniendo preeminencia las más pobres. El nombramiento de la dote se hacía en cabildo general. El segundo es el de Álvaro Martín, de parecidos fines, aunque en este caso las adjudicaciones correspondían en primera instancia a los familiares del fundador, en segundo a los feligreses de la Magdalena y, si no hubiera casos a dotar, se dejaba la elección a la conciencia de los alcaldes y mayordomo. El nombramiento de estas dotes se producía de forma irregular, pues dependía que la administración de los patronatos tuviese la suficiente liquidez, aspecto que se repitió durante todo el siglo $\times \mathrm{V} I I^{26}$.

25 Esta es una grave problemática que hipoteca en demasia a la corporación y le impide una actividad cultual y espiritual más dinámica. Se detectan diversos conflictos con cobradores, y en bastantes ocasiones. el propio Mayordomo de Hacienda debia ocuparse de sus funciones.

26. Archivo Sacramental de la Magdalena, libro de Cuentas. 1747. Estos patronatos tenían una dotación de 50 ducados. Se conoce que el de Álvaro Martín contaba con una casa en la calle Galera y otra en Triana. junto a San jacinto. además de dos juros de heredad en Llerena (Actas capitulares de 9-3-1732, 26-7-1735. 5-2-1736 y 2-3-1738).

Como caso excepcional en cabildo de 31-12-1773 se dotaron siete hijas de cofrades por el pa tronato de Miguel Jerónimo. 
La Cofradía del Rosario de San Pablo no fue ajena al fenómeno rosariano popular, sino que, conservando sus esquemas, trató de integrarse en él, aunque sus limitaciones jurisdiccionales, el lastre de la administración de numerosas rentas y tributos (que burocratizaban en exceso sus actividades) y su carácter elitista lo hicieron prácticamente imposible. La religiosidad rosariana que propugnaba, en uniformidad con la Orden de Predicadores y la generalidad de las cofradias, ciertamente era más coherente desde el punto de vista de la ortodoxia católica, pero no evolucionó hacia las prácticas más espontáneas y externas que otorgó al Rosario en Sevilla una personalidad propia, en donde realmente se palpaba una vida activa, participativa, abierta, que ciertamente conectaba más con el pueblo, verdadero fundador de las hermandades diocesanas. La Cofradía significaba un marco cerrado con unas normas ya estipuladas, que habían perdido la adaptabilidad necesaria para contactar con el pueblo.

Esto hizo que su ámbito devocional disminuyera en beneficio de las hermandades diocesanas templarias y extratemplarias, y entrara en una dinámica descendente en todos los órdenes de su actividad, aunque evidentemente contaba con un núcleo a considerar de cofrades y fieles y gozaba -como ha quedado dicho- de un patrocinio espiritual, al que se subordinaban el resto de las corporaciones rosarianas. Ciertamente la generalización del Rosario y la pérdida efectiva del monopolio de la devoción, provocó una crisis importante entre los cofrades que durante mucho tiempo no se resignaron a la realidad ilegal, pero realidad. También hay que admitir que la religiosidad de estas cofradias supuso un complemento a las otras manifestaciones más populares de los Rosarios callejeros, y de alguna manera ambas presentan una imagen más completa del fenómeno en Sevilla, aunque evidentemente contrastada y con un desequilibrio paiente en su incidencia real y profunda.

\section{LA CONGREGACIÓN DE NUESTRA SEÑORA DEL CONSUELO}

Ciertamente se trata de una corporación promovida por la comunidad dominica de San Pablo, uno de cuyos frailes es el capellán y bajo su jurisdicción, pero que gozá de amplia autonomía en su gobierno e instituto y que cuenta con notable arraigo en el vecindario. Es curioso percibir como en el mismo ámbito de! convento. subsisten una cofradia institucional rosariana, practicandio el uso de la devoción con carácter interno e integrando cofrades de recoriocido protagonismo social, con esta otra congregación eminentemente popular centrada en el uso público de la devoción y con casi todas las caracteristicas de una hermandad secular. Ambas dependen 
en última instancia de la Orden, pero esta última adquiere idiosincrasia propia, y marca su propia estructura institucional, mientras que la primera se halla constreñida a los cánones generales de las cofradías dominicas y muy probablemente su carácter no ciertamente popular quisiera establecer diferencias frente a otros cofrades más arraigados en el pueblo.

Esta congregación constituye, pues, un dato significativo sobre la pastoral de la Orden de Predicadores sobre la religiosidad popular en torno al Rosario, una devoción propia de la Orden que, tras muchos siglos de fomento y control directo, pierde su exclusivo carácter dominicano y se convierte en todo un fenómeno de masas, imposible de controlar y monopolizar a pesar de los muchos pleitos y recursos promovidos frente a corporaciones rosarianas surgidas en parroquias, conventos no dominicos o extratemplarias. Desde sus conventos continúan promocionando la devoción, su uso interno y externo y cuentan para ello también con las cofradías institucionales, pero es obvio que no es suficiente para una promoción popular directa y efectiva como la que conseguía un padre Ulloa en los años finales del siglo XVII, con sus predicaciones ante ingentes multitudes de fieles, que propiciaron en último efecto la popularización de los Rosarios callejeros ${ }^{27}$.

De todo aquel fervor rosariano en torno al convento de San Pablo surgieron congregaciones espontáneas dedicadas al uso del Rosario público por las calles de la feligresía y sobre las que la comunidad de San Pablo ejercía una cierta coordinación. Una de ellas es la que nos ocupa y que residía en la iglesia del propio cenobio. Todo hace pensar que la Orden Dominica encontró en el fomento de estas corporaciones, surgidas entre el propio vecindario, un cauce adecuado para su pastoral entre el pueblo, más allá de carismas personales (aunque siempre eran necesarios) y como alternativa a la oficialidad demasiado enconsertada de las cofradías rosarianas. Ciertamente este cauce fue efectivo, a pesar de la dificultad y los no pocos prejuicios existente hacia la religiosidad popular y su espontaneidad casi heterodoxa, así como a sus peculiares maneras de concebir el uso público de los rosarios. En definitiva, el riesgo de otorgar la, por otra parte necesaria, autonomía al pueblo en el uso devocional del Rosario. No obstante, esta corporación, aunque popular, no es equi-

Sobre la personalidad del P. Pedro de Santa María de Ulloa. vid. sobre todo, ARANDA, Gabriel, Vida del siervo de Dios, ejemplar de sacerdotes, el venerable padre Fernando de Contreras. Sevilia, 1692, págs 89 ss. Este fraile convirtió al convento de San Pablo en el centro rosariano por excelencia. Es difícil entender la eclosión de los rosarios públicos sin el clima de exaltación mariana provocado por sus prédicas. 
parable a otras hermandades más en la base de la población, me refiero a las radicadas fuera de los templos y, por tanto, su espontaneidad es un tanto limitada.

Esta congregación surge a finales del siglo XVII o principios del XVIII, sin duda, a raíz de las predicaciones de Ulloa y el posterior desarrollo de los rosarios públicos. Aunque no hay constatación documental sobre los origenes y primer desarrollo histórico, sí se hace referencia al mismo en el libro de actas conservado en el archivo del Arzobispado, y que va a servirnos de base fundamental para el estudio del acontecer de esta congregación durante el siglo XVIII, al abarcar desde 1736 a $1786^{28}$.

En este apartado voy a tratar de analizar las características primordiales del instituto y gobierno de esta entidad y, sobre todo, las motivaciones que inspiran a sus cofrades, sus actitudes frente al vecindario, comunidad religiosa, y las relaciones entre ellos: sentido de hermandad, personalismos, conflictos y rivalidades...así como las dificultades económicas que han de afrontar para el mantenimiento de la devoción y hermandad. Lamentablemente, la exigua documentación nos impide realizar un estudio más específico como en el caso de la Cofradía.

Se trata de una corporación rosariana, aunque propiamente la advocación de la Titular no era la Virgen del Rosario, sino del Consuelo. No obstante, el instituto fundamental es la salida del Rosario público. Durante el siglo XVIII son muchas las hermandades de gloria con una advocación mariana distinta a la del Rosario o de un santo, e incluso sacramentales que incorporan a su título el del Rosario. Casos concretos pueden ser, por ejemplo, la hermandad de Nuestra Señora de la Alegría, de la parroquia de San Bartolomé, la de la Virgen de Europa de las Pasaderas de San Martín, la de Santa Ana en su parroquia de Triana, la de Jesús Sacramentado de San Hermenegildo ${ }^{29}$ y otras muchas. Incluso en las hermandades propiamente denominadas de la Virgen del Rosario, el instituto fundamental era la procesión pública por las calles y no el culto a la imagen titular propiamente dicha.

28 Archivo General del Afizozispado, Sección III., Serie Hermandades, legajo 12.

29 Esta tiermandad, fundada en torno a 1670 , se titulaba de Jesús Sacramentado, Nuestra Señora del Rosario y Santo Cristo Crucifıcado, aunque su instituto príncipal era el culto sacramental. La devoción del rosario era interna en forma de rezo comunitario en la capilla. La denominación rosariana parece derivar de los efectos de las misiones jesuiticas de 1669, dirigidas entre otros por el padre Tirso González de Santalla. Sobre este religioso, que llegó a ser prepósito de la Compañía, vid.: Reyero, Elias, Misiones del P. Tirso González (1665-1686). Santiago de Compostela, 1913. 
La razón de crear estas hermandades era consolidar el ejercicio público. Es una religiosidad dinámica donde la imagen concreta no es lo más importante, sino el propio uso rosariano. Cuando se produzca la crisis de la religiosidad barroca a tinales de esta centuria, muchas de estas entidades desaparecerán o centrarán su instituto en la imagen de su advocación, que en algún caso ni tenía una plasmación física.

\section{Origenes y primer desarrollo histórico}

Sobre los orígenes de la congregación que nos ocupa, primeras motivaciones de los devotos y características de la incipiente entidad, es bien expresivo el tenor del primer acta de este libro de acuerdos. Parece bien claro un rasgo de esta iniciativa popular: la espontaneidad y la plena autonomía con la que desenvolvían en su instituto a pesar de la indudable influencia, aunque indirecta, de los frailes en la promoción y mantenimiento de la devoción. Se detecta así que, tras unos primeros años de fervor rosariano, poco a poco conflictos personales entre los cofrades y la propia rutina de la cotidianidad hizo que el uso rosariano decayese al punto de permanecer la corporación en un estado de práctica extinción. Se observa asimismo la precariedad con la que nace y se mantiene la corporación, y como el apoyo del vecindario es fundamental para la supervivencia. En un primer momento, es tal el concurso de cofrades, que han de organizarse dos procesiones: prima noche y madrugada.

"Dicha llamada y junta era al fin de que se hiciese por dichos congregados, si les parecía una nueva obligación de servir con más mérito a la Virgen Saritisima del Consuelo pues el motivo era la experiencia que tenía de la poca asistencia a el Rosario y poco aumento en las alhajas precisas para el culto y adorno del altar de la Madre de Dios, nacido todo de la poca unión de los congregados, pues habiéndose mantenido el Rosario sin especial orden, señalado para el gobierno quería cada uno prevaleciese su dictamen, de que se habian seguido algunos disturbios en menoscabo de la asistencia de él y menor aumento de la devoción de la Señora, $y$ que queriendo poner a esto el debido remedio, hizo presente como por el año de 1704 se habian impreso en dicho Rosario (siendo capellán del mismo el padre Alonso Ponce) unas cartas de esclavitud por las cuales prometia cada uno que la tomaba asistir toda su vida a el Rosario para por este medio solicitar de la Madre de las Misericordias el consuelo para sus almas y que estando ya perdida o totalmente olvidada esta santísima devoción que habia sido en lo pasado estímulo eficaz para mantener y atraer a el ejercicio santo de la angélica salutación acompañando todas las noches y madrugadas por las calles a la Madre de Dios con solemne culto y que quedan dichos en este escrito. era su ánimo situarla de nuevo 
entre los congregados que quedan dichos en este escrito, pareciéndole también muy conducente a el aumento de este Rosario y continuo culto de él nombrar a algunos de dichos congregados algunos oficios para el mejor orden y gobierno..." ${ }^{30}$.

Este primer cabildo tiene efecto en la capilla del Cristo de Montserrat. No tenían una sede concreta para reuniones y utilizaban diversas dependencias, aunque la mayoría de los cabildos suelen celebrarse en la sacristía de la capilla del Niño Perdido. Las primeras disposiciones se refieren a la organización del Rosario y elección de los cargos de gobierno. Se hace recuento de las insignias y se detecta la necesidad de su renovación. Eran pocos los cofrades y han de recurrir a los hermanos de mayor carisma para el reparto de las principales insignias. Era necesario recuperar la devoción en el barrio.

Al año siguiente, la corporación dispone de la necesaria infraestructura para organizar la Novena anual de septiembre, culto principal de su instituto, y que consistía en la celebración de sendos Rosarios de Gala que durante nueve dias acudian a iglesias distintas a realizar su estación. Igualmente se aprueban unas reglamentaciones para el gobierno de la congregación.

Este Rosario de Gala o procesión extraordinaria de septiembre, es lo que se denomina en otras corporaciones "Novena de calle», y era una práctica usual en los días de la festividad de la imagen titular, en este caso, Nuestra Señora del Consuelo.

\section{El Rosario y las demarcaciones socio-reiigiosas de la feligresia. Actitudes que subyacen}

Con la restauración de la hermandad y su Rosario, éste volvió a integrarse en la geografía devocional de la feligresia y en ios itinerarios de los distintos rosarios que tenian su sede en los alrededores. Igualmente, debía observar distintas normas tradicionales de armónica relación entre ellos, ceremonias, protocolos de cortesía, en definitiva, toda una liturgia de la religiosidad popular rosariana. Todo ello se recoge en un acta capitular, pues se hacía necesario establecer unos criterios sobre recibimientos de rosarios ya que, concretamente algunos, hacian estación de forma asidua a la 
iglesia-sede del que historiamos, caso por ejemplo de los del Postigo del Aceite ${ }^{31} \mathrm{o}$ el de la calle de la Mar.

«Siempre que vinieren rosarios en estación a nuestra iglesia de los que salen de varios retablos de las calles, se reciban con el Simpecado o pendón que sale todas las noches, añadiendo a éste otros dos faroles altos más que todos lo pagen seis, asimismo dos faroles bajos grandes delante del pendón y que los sujetos que lleven los faroles altos, imagen y cruz vayan vestidos a lo militar, sin añadir otra cosa alguna. Y si el rosario que viniere a hacer estación fuese de las que tienen su asiento en alguna iglesia se añadia el sacar el pendón nuevo y si se le debieren especiales atenciones, se añadirán cohetes [...] pero al mismo tiempo se advierte que por ningún acontecimiento se saque para recibimiento de rosario la imagen de la Madre de Dios en nuestro altar, sino es sólo en nuestra Novena y se ofrece alguna rogativa o en el estreno de algún pendón que hayan traído a bendecir a nuestra iglesia”.

De este texto pueden extraerse, además, algunas consideraciones muy importantes: se establecen diferencias en el protocolo de los recibimientos según se trate de un rosario establecido en un recinto sagrado o tenga su sede en un retablo callejero, con un claro sentido discriminatorio. Este detalle, junto a la prohibición de utilizar la imagen titular en estas "liturgias", nos indican un cierto control en pro de una purificación de la espontaneidad característica de los rosarios, sin duda por justos motivos procedentes de conflictos derivados de conflictos conocidos entre algunos de estos cortejos, bien en la ciudad, o incluso en la feligresía y este control sin duda, proviene directa o indirectamente del ámbito jerárquico eclesial, concretamente de la comunidad dominica, uno de cuyos frailes era el capellán de la hermandad, como queda dicho. La discriminación negativa hacia las congregaciones rosarianas con sede en la propia vía pública supone, por un lado, un prejuicio hacia unas formas poco ortodoxas de expresión de la fe, derivada no sólo de una actitud eclesial, sino de los propios cofrades que se sienten dotados de un superior status religioso y también social y, por otro, expone la constante inquietud por la propia supervivencia de la entidad ante la competencia "desleal» de asociaciones

31 Sobre este rosario, cabe decir que pertenecia a la Hermandad de la Pura y Limpia Concepción de la Virgen, radicada en la capilla-retablo que todavia subsiste en el Postigo del Aceite. Sobre algunos aspectos de esta hermandad, puede consultarse mi artículo "Aproximación al estudio de los esquemas de religiosidad sevillana que conoció fray Diego de Cádiz" en Estudios Franciscanos. Homenaje a fray Diego José de Cádiz, vol. 96, n." 414, Barcelona, septiembre-diciembre 1995. págs. 365-387. 
espontáneas, y un tanto irregulares, que privaban de devotos a su rosario, amén de la mengua económica procedente de las demandas públicas y donativos del vecindario.

Este carácter de congregación con sede en un templo implica, pues, unas determinadas actitudes "clasistas" en sus cofrades, y sin dejar de ser una corporación propia de una religiosidad del pueblo, sin embargo, se diferencia de esa otra devoción ciertamente más irregular desde el punto de vista eclesial, pero más cercana e identificada con la gran masa de la población, especialmente entre el vecindario más humilde.

En el fondo subyace también, como he indicado, esa diferente concepción de lo sagrado en la devoción de los rosarios. No resulta ciertamente idéntico hacer estación desde un recinto templario, para recorrer las calles y plazas del vecindario, portando la imagen del Simpecado y el propio rezo avemariano y bajo la dirección de un fraile dominico, que salir del propio entorno del barrio y donde el retablo y las insignias representan un signo de identidad muy característico, pues todos lo sienten suyos. Podría decirse que lo sagrado, en el primer caso, viene al pueblo, mientras que en el segundo, ya está allí.

No obstante esto, hay que decir que en las actas se hacen continuas menciones a rosarios de corporaciones extratemplarias, como las dos anteriormente nombradas, la del Rosario de la Puerta Real o la del Cristo de la Expiración y Nuestra Señora de los Dolores, sita en los bajos de los portales de la Plaza de San Francisco, que, en ocasión del estreno y bendición de su Simpecado en el convento de San Pablo, solicitaban a esta congregación que fuera su madrina en el acto y la acompañara hasta el cenobio desde su sede ${ }^{32}$.

Estas eran algunas de las salidas extraordinarias del Rosario de esta corporación, que formaban parte de estas liturgias mencionadas. Era frecuente y signo de cortesía acudir a las celebraciones organizadas por otros rosarios. Se ha constatado el caso de una congregación humilde, pero el indudable prestigio con que contaba nuestra congregación, la hacia merecedora de participar también en eventos de corporaciones más poderosas económica y socialmente. Esto ocurrió en 1738 con ocasión de la

32 Acta capitular de 21-5-1786. Esta corporación empezó a organizar su rosario de prima noche el 11 de diciembre de 1757. Poseía un pequeño retablo con un lienzo en que se representaban sus titulares. En un expediente formado en 1760 , se indica un inventario de bienes en que aparece mencionado un simpecado de tafetán carmesí, que es el que ahora se renueva sin duda en mejor tejido. (Sección III, Serie Hermandades., legajo 21). 
bendición de un Simpecado con la efigie de Nuestra Señora de la Antigua, para el Rosario que salía de las Gradas de la Catedral, acto estrechamente relacionado con la hechura de un retablo de piedra jaspe para la efigie de la Virgen de la Antigua, sita en el templo metropolitano. Ambas empresas habían sido por iniciativa del prelado de la diócesis, Luis de Salcedo y Azcona, quien había convocado a todos los rosarios de la ciudad. El propio Provincial de los dominicos ordenó la participación de los cofrades de esta hermandad. En este acto tuvo especial protagonismo la congregación del Consuelo, pues su Simpecado, junto al del Colegio de Santo Tomás, fueron designados para escoltar al de la Antigua al oratorio del arzobispo donde sería bendecido ${ }^{33}$.

\section{El Rosario público: Elementos materiales y formales}

El Rosario de corporación va incrementando su patrimonio, y son constantes las noticias de nuevas adquisiciones, en especial para la Novena de septiembre. Se cuidan con sumo esmero, tanto los elementos materiales como formales, referentes al rezo y compostura de los cofrades. Así, por ejemplo, en lo que respecta a las Novenas, cabe indicar, en cuanto a elementos materiales, los instrumentos musicales: clarín delante de la cruz y dos violines, violón y bajo en el coro del rosario.

Aunque el Inventario de bienes que se conoce documentalmente data de 1783, nos sirve efectivamente para conocer algunos detalles de importancia respecto al uso rosariano. Se mencionan tres simpecados: para la Novena o de Gala, para diario y el que se utilizaba en ocasión de las Rogativas. No se detalla una descripción física y hubiera sido interesante comprobar si el de Rogativas era morado, y si este tipo de rosario podria equipararse a los penitenciales o incluso de ánimas, como acontecia en otros rosarios en el que el simpecado penitencial era el de difuntos. Singular es el caso del lienzo de un simpecado de difuntos o penitencial, conservado por la Hermandad del Rosario de los Humeros y que representa a la Virgen, con atuendo de luto, al pie del Calvario. No obstante, las propias Rogativas, por su frecuencia, constituía un motivo suficiente para confeccionar un simpecado particular, aunque sólo se hace mención de la asistencia a una Rogativa en 1784, por lo que cabe pensar que fue adqui-

3. Acta capitular de 21-9-1738 y nota adicional del acontecimiento tal y como la redactó Bernardo Román Lazo, escribano de Su Majestad y que circuló impresa. 
rido en la reorganización y, por otro lado, no parece claro que dispusieran de un simpecado especial para las novenas de ánimas. Hay dos cruces, una de plata para el Rosario de Gala y otra de madera con el INRI y cantoneras de plata. Respecto a las insignias, se mencionan 10 faroles altos con sus varas para el de Gala y otros 16 para diario, 4 estrellas de cristal (quizá para el de Gala) y 24 faroles bajos, aparte ya de dos demandas, campanillas y otros utensilios menores ${ }^{34}$.

En los aspectos formales, se resalta la necesidad de los ensayos del coro que actuara en cada procesión, la conveniencia que estén todos los faroles dispuestos y encendidos antes de comenzar el rezo de los primeros dieces del rosario, y no hacerlo con prisas cuando ya sale la comitiva y, por supuesto, el aspecto económico, estableciendo tres demandas todas las noches de la Novena y una limosna voluntaria entre los asistentes para el pago de la cera.

En lo que se refiere a los integrantes de la comitiva, se dedica especial atención a los sacerdotes que prediquen y al hecho de que en la comitiva figuren todos los militares que fuere posible convidar, aparte de los congregados que lo fuesen, para llevar los faroles altos y bajos ${ }^{35}$.

Esto manifiesta otra actitud característica de estos cofrades y de la propia corporación: la importancia de las formas en su religiosidad. Es constatable la preocupación por prestigiar un Rosario, sobre todo entre las corporaciones eclesiales o templarias, y un signo más de esa rivalidad ya comentada, entre rosarios en pro de un lugar de predominio en la geografía devocional de la ciudad. Por lo expuesto, parece indicarse también la presencia de militares entre los cofrades de la Virgen del Consuelo.

Dentro del instituto rosariano era muy importante el sufragio por los difuntos, y era obligado aplicar determinados días de la procesión diaria al alma de los cofrades o devotos que fallecian. Pero este instituto adquiría especial realce en el mes de noviembre. Esta corporación, al igual que otras, decidió en 1743 la organización de una Novena de ánimas, pero con una característica muy peculiar: el cortejo adquiriría la forma de un Rosario de Madrugada, uso ciertamente extendido por las congregaciones sevillanas, pero en este caso sólo circunscrito al sufragio por los difuntos. El tenor del acuerdo manifiesta la importancia de este Rosario.

3a Acta capitular de 11-9-1783. Sobre el lienzo del simpecado de los Humeros, vid. mi monografía El Rosario de los Humeros: estudio histórico y patrimonial..., Sevilla, 1993, pág. 56.

35 Actas capitulares de 23-8-1739 y 28-10-1739. 
«Se acordó el que para más servir a Dios Nuestro Señor y obsequiar a la Virgen Santísima y para alivio y descanso de las benditas ánimas que en prisiones de fuego están detenidas en las llamas del Purgatorio se saque el Rosario (que sale de noche de Nuestra Madre y Señora del Consuelo con los mismos faroles) por las madrugadas, haciendo las estaciones que de noche en el discurso del año se practican, para con este medio aliviarlas de las penas que padecen y que dicho Rosario salga con el Simpecado de la Madre de Dios de la capilla de la Antigua que está en el compás del dicho real convento de San Pablo y que para ello se hagan cédulas de convite para este efecto para los demás ausentes y devotos del santísimo rosario, citando para las cuatro de la madrugada del día dos del mes próximo que viene de noviembre, día de los difuntos, en el cual se da principio a dicha Novena y se finalizará el día 10 de dicho mes y que cuando el Rosario vuelva a dicha capilla se diga una misa rezada, aplicándola con lo demás que se rece por las ánimas ${ }^{36}$.

\section{Crisis generalizada. El declinar de la corporación}

A partir de 1748 la corporación sufre una grave crisis institucional. Ya en los años anteriores, existían muy graves dificultades para la celebración de las novenas y, concretamente en 1745, pudo llevarse a cabo la de octubre merced a la limosna extraordinaria de un bienhechor. Las actas se interrumpen. Todo parece indicar que cayó en una irremediable decadencia e interrumpió las prácticas de su instituto, el Rosario público, que no se reanudan junto con la elección de nuevos oficiales hasta diciembre de $1782^{37}$.

En el primer acta, tras su nueva restauración, se constata el estado de práctica extinción de la hermandad y los muy escasos devotos que concurrían al rosario. Solían reunirse ahora en la capilla de Montserrat.

La iniciativa de la restauración surge en parte de la propia comunidad de dominicos, cuyo prior anima a los cofrades a reemprender el uso rosariano. En este primer cabildo, se nombra un hermano mayor, Fernando Calderón Reina, como cabeza de un grupo de 20 diputados encargados de organizar toda la corporación.

Una de las principales preocupaciones era la económica. No era tarea fácil reinsertarse en la feligresía con el Rosario, y las demandas no surtían un efecto adecuado, aparte la propia dificultad de repartirlas entre los cofrades.

36 Acta capitular de 28-10-1743.

37 Acta capitular de 1-12-1782. 
A pesar de todo, merced a las constantes iniciativas del Hermano Mayor, se pudo consolidar el instituto en los primeros años, y de hecho, se observan las salidas regulares del rosario de prima noche diario y los de Gala en las Novenas, así como incluso uno de Rogativas en 1784. También se hace mención de un cortejo rosariano para cantar un responso ante el cadáver de un religioso carmelita del Santo Ángel, a requerimientos del propio superior del cenobio ${ }^{38}$.

Pero lo cierto es que desde el comienzo se observan las dificultades en la administración de la hermandad, en la escasez de cofrades dispuestos a ayudar en la consecución de recursos, en la organización del rosario. Hay ciertas discrepancias respecto a la hora concreta de salida y no siempre se establecía con tiempo, y eso desorientaba a los devotos. En todo caso, seguía siendo a prima noche, concretándose ya después media hora después del toque de oraciones. Atención importante se dedica al cuidado del orden y compostura en la procesión, pero faltaba lo más importante: la presencia de fieles.

Es una época ciertamente de decadencia en la religiosidad rosariana y los rosarios carecen ya del apego popular de comienzos de siglo. Son comitivas con escaso concurso de devotos donde incluso, se "alquilan" a personas para poder organizar la procesión. Por esta razón, esta corporación acuerda nombrar un celador en el Rosario "[...] para la guardia y custodia de los niños del coro y que no vayan jugando ni menos alborotando, dando carreras por el rosario y quebrando los faroles, y que por este hecho no sea la irrisión de los demás rosarios."

Todo ello nos indica una gran dificultad para atraer de nuevo a la feligresía en su participación del Rosario. Cuando en un rosario se dan incidentes como los descritos, circunstancia muy común por estas fechas, quiere significar que la práctica era meramente una forma estética sin verdadera devoción. Era ya tarde para conseguir de nuevo el apoyo de la feligresía.

Esta segunda y última restauiración de la entidad es muy efímera. Los cofrades no se comprometen al reparto de demandas - como queda dicho--, falta ilusión. Se patentiza una conciencia de rutina, de que este tipo de religiosidad no genera una devoción efectiva. Han desaparecido ya muchos rosarios. Se siguen organizando las Novenas de septiembre, pero son costeadas por el Hermano Mayor Nicolás de Aguirre, al que se

38 Acta capitular de 9-11-1784. 
le otorga este cargo con carácter perpetuo ${ }^{39}$. Cuando este cofrade fallece en 1786, prácticamente se extingue la corporación.

En apretada síntesis, he trazado el perfil de una congregación rosariana ciertamente peculiar, con sede en el real convento de San Pablo, bajo jurisdicción de los dominicos, pero dotada de amplia autonomía desde la propia fundación por feligreses de la collación en pleno fervor rosariano de finales del siglo xVII. No obstante, la tutela dominica indirectamente se hace notar en determinados momentos de su trayectoria institucional y es precisamente esta circunstancia, a la que va lógicamente unida el hecho de residir en un ámbito templario, lo que la aleja de la religiosidad más popular de corporaciones creadas por los propios vecinos en retablos callejeros, con las que sostiene unos ciertos conflictos de competencia. 